\title{
POTENCIAL DE BIOCATÁLISE ENANTIOSSELETIVA DE LIPASES MICROBIANAS
}

\author{
Patrícia de O. Carvalho*, Silvana Ap. Calafatti, Maurício Marassi, Daniela M. da Silva, Fabiano J. Contesini e Renato \\ Bizaco \\ Faculdade de Farmácia, Universidade São Francisco, Av. São Francisco de Assis, 218, 12916-900 Bragança Paulista - SP \\ Gabriela Alves Macedo \\ Departamento de Ciência de Alimentos, Faculdade de Engenharia de Alimentos, Universidade Estadual de Campinas, CP 6121, \\ 13083-970 Campinas - SP
}

Recebido em 18/5/04; aceito em 12/11/04; publicado na web em 13/4/05

\begin{abstract}
POTENTIAL OF ENANTIOSELECTIVE BIOCATALYSIS BY MICROBIAL LIPASES. Microbial lipases have a great potential for commercial applications due to their stability, selectivity and broad substrate specificity because many non-natural acids, alcohols or amines can be used as the substrate. Three microbial lipases isolated from Brazilian soil samples (Aspergillus niger; Geotrichum candidum; Penicillium solitum) were compared in terms of their stability and as biocatalysts in the enantioselective esterification using racemic substrates in organic medium. The lipase from Aspergillus niger showed the highest activity (18.2 U/mL) and was highly thermostable, retaining $90 \%$ and $60 \%$ activity at $50{ }^{\circ} \mathrm{C}$ and $60{ }^{\circ} \mathrm{C}$ after 1 hour, respectively. In organic medium, this lipase provided the best results in terms of enantiomeric excess of the (S)-active acid (ee $=6.1 \%$ ) and conversion value $(\mathrm{c}=20 \%)$ in the esterification of $(R, S)$-ibuprofen with 1-propanol in isooctane. The esterification reaction of the racemic mixture of $(R, S)$-2-octanol with decanoic acid proceeded with high enantioselectivity when lipase from Aspergillus niger $(\mathrm{E}=13.2)$ and commercial lipase from Candida antarctica $(\mathrm{E}=20)$ were employed.
\end{abstract}

Keywords: lipases; enantioselectivity; $(R, S)$-ibuprofen.

\section{INTRODUÇÃO}

A biocatálise é hoje um dos campos mais promissores dentro das novas tecnologias para síntese de compostos de alto valor agregado. A exploração da biodiversidade na busca de novos catalisadores por técnicas de seleção de microrganismos, de plantas ou células animais representam os métodos tradicionais de descoberta de novas enzimas para o desenvolvimento da biocatálise em escala industrial $^{1}$. Os microrganismos neste caso são de particular interesse devido ao curto período de geração, à grande diversidade de processos metabólicos e enzimas envolvidas e, não há um número limitado de microrganismos na natureza que possam ser testados, os quais são bastante diferentes entre si. Microrganismos isolados em território brasileiro têm demonstrado excelente potencial biocatalisador frente a diferentes substratos orgânicos de interesse, como por ex. na hidrólise de óleos marinhos ${ }^{2,3}$, na síntese de ésteres de ácidos graxos poliinsaturados $^{4} \mathrm{e}$ de ésteres de aroma ${ }^{5}$.

Dentre as enzimas hidrolíticas de maior interesse estão as lipases (glicerol ester hidrolase E C. 3.1.1.3), que são biocatalisadores versáteis capazes de catalisar diferentes reações, tanto em meio aquoso como em meio orgânico, com teor de água restrito. Entre as lipases de vegetais, animais e microbianas, estas últimas são as mais utilizadas e, na sua grande maioria, não são nocivas a saúde humana, sendo reconhecidas como "Generally Regarded as Save -

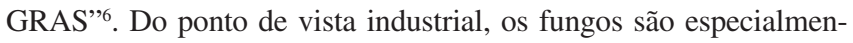
te valorizados porque as enzimas por eles produzidas normalmente são extracelulares, o que facilita sua recuperação do meio de fermentação ${ }^{7}$. Os trabalhos replatados em literatura sobre lipases fúngicas são numerosos, sendo que os mais extensivamente estudados são os fungos Geotrichum candidum, Aspergillus niger,

*e-mail: patcarvalho@saofrancisco.edu.br
Aspergillus oryzae, Rhizopus delemar e Penicillium cyclopium ${ }^{8}$. As lipases têm sido utilizadas em uma variedade de segmentos biotecnológicos, como em indústrias de alimentos (desenvolvimento de aromas e maturação de queijos), de detergentes, óleoquímica (hidrólise de óleos e gorduras, síntese de biosurfactantes) e para tratamento de resíduos oleosos provindos da indústria do couro e de papel. Uma aplicação que tem merecido destaque é sua utilização na obtenção de fármacos ou insumos farmacêuticos em suas formas enantioméricas ativas com elevada pureza ótica, pois estas enzimas são capazes de reconhecer moléculas quirais e atuam, preferencialmente, em um dos isômeros de uma mistura racêmica ${ }^{9}$. É conhecido que alguns fármacos são produzidos e comercializados na sua forma racêmica e que a atividade biológica depende, em muitos casos, de sua configuração absoluta. Normalmente um dos isômeros $(R$ ou $S$ ) apresenta atividade biológica, enquanto o outro é menos ativo ou até mesmo tóxico. Na grande maioria dos casos, os fármacos administrados sob a forma racêmica possuem características biológicas muito inferiores aos seus enantiômeros puros ${ }^{10}$. O ibuprofeno [ácido ( \pm )-2-(4-isobutilfenil) propiônico] é um ex. interessante de medicamento que ainda é vendido como mistura racêmica. Relatos tem comprovado que a forma $S$ do ibuprofeno é 160 vezes mais ativa que a forma $R$ na síntese de prostaglandina in $v_{\text {itro }}{ }^{11,12}$. Um grande investimento em pesquisas tem sido feito para desenvolver diferentes processos para obtenção da forma enantiomérica ativa deste fármaco. $\mathrm{O}$ produto opticamente puro tem um valor comercial maior que o racemato, mas a produção tem sido limitada por dificuldades legais e de processo $^{13}$.

A importância do uso de enzimas em biocatálise tem se mostrado cada vez mais evidente grande versatilidade de reações catalisadas, condições brandas de reação, natureza regio, quimio e enantiosseletiva são algumas de suas vantagens ${ }^{14,15}$. A reação de esterificação enantiosseletiva catalisada por lipases tem sido usada com sucesso na resolução dos profenos ${ }^{16-18}$. Uma forma bastante 
simples de obter a forma $(S)$-ativa presente na mistura racêmica do fármaco é realizar a reação de esterificação utilizando lipase que apresente enantiosseletividade para a forma $(R)$-ibuprofeno. Desta forma, a enzima catalisa seletivamente a conversão para $(R)$-éster, discriminando o $(S)$-ibuprofeno da mistura racêmica, conforme ilustrado no Esquema 1. Posteriormente, o ácido discriminado, $(S)$ ibuprofeno, pode ser separado do meio de reação reagindo-o com uma base forte em meio aquoso.

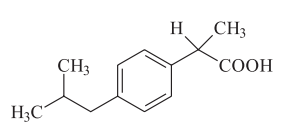

$(R, S)$ - Ibuprofeno
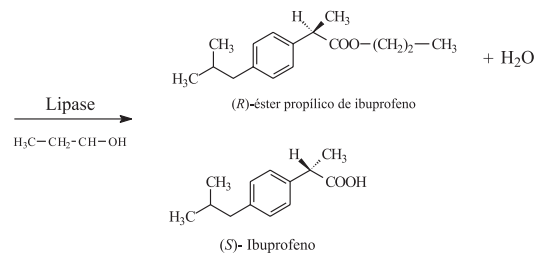

Esquema 1. Esterificação enantiosseletiva do (R,S)-ibuprofeno com 1propanol catalisada por lipase com enantiopreferência para o $(R)$-ibuprofeno

Considerando a extraordinária diversidade microbiana e a importância dos fungos como produtores de enzimas, justifica-se a busca de novos biocatalisadores com características especiais e passíveis de aplicação em biocatálise. Baseado no exposto, este trabalho teve como objetivo estudar algumas propriedades de lipases obtidas de cepas isoladas em território brasileiro, para uso em biocatálise orgânica, tais como termoestabilidade, estabilidade frente ao $\mathrm{pH}$ e à enantiopreferência destas enzimas na esterificação do (a) $(R, S)$-ibuprofeno com 1-propanol e do (b) $(R, S)$-octanol com o ácido decanóico em meio orgânico.

\section{PARTE EXPERIMENTAL}

\section{Materiais}

Os procedimentos de fermentação foram realizados utilizando-se extrato de levedura e bacto-peptona obtidos da Difco Chemical Co. Detroit, USA. Os outros componentes do meio de cultura e os reagentes químicos e solventes usados na esterificação foram adquiridos da Merck. A peneira molecular, os padrões usados para as análises cromatográficas, assim como as formas enantioméricas puras do fármaco, foram adquiridos da Sigma Chemical Co. St. Louis, USA. O álcool racêmico, 2-octanol, e suas formas enantioméricas puras foram adquiridos da Aldrich Chemical. Foi utilizado para a curva padrão o ácido oléico puro da marca Synth. O azeite de oliva extra virgem (baixa acidez) e o $(R, S)$-ibuprofeno foram comprados em estabelecimentos comerciais do local. A lipase de Candida antarctica (Novozyme 435 - Tipo B) imobilizada em resina acrílica foi gentilmente cedida pela Novozymes Latin America Ltda e a lipase bruta de Candida rugosa (Tipo VII) foi adquirida da Sigma Chemical Co.

\section{Microrganimos}

Os fungos utilizados foram isolados de amostras de solo próximas a plantações de cana-de-açúcar na região de Bueno Brandão, Minas Gerais, Brasil, utilizando placas de petri contendo o meio batata dextrose ágar (BDA $)^{2}$. As colônias de fungos isoladas foram repicadas em tubos de ensaio $(10 \mathrm{~mL})$ contendo o mesmo meio e, após crescimento satisfatório, armazenadas em geladeira $\left(5^{\circ} \mathrm{C}\right) \mathrm{e}$ repicadas a cada 20 dias para sua manutenção. Os fungos foram devidamente identificados e depositados (com cláusula de confidencialidade) na Coleção de Cultura do Centro de Micologia da Universidade de Lisboa (Portugal). Antes do início de cada fermentação para produção da enzima, cada cepa foi repicada em tubos de ensaio $(10 \mathrm{~mL})$ contendo o meio BDA, deixada para crescimento em câmara de incubação (BOD - Fanem 347-CD) por um período de 6 a 9 dias em temperatura constante de $30^{\circ} \mathrm{C}$, e utilizada para obtenção do inóculo (suspensão homogênea de esporos) de fermentação.

\section{Produção de lipases}

$1 \mathrm{~mL}$ da suspensão homogênea de esporos, contendo de $10^{7} \mathrm{a}$ $10^{8}$ esporos foi obtido após raspagem da superfície do meio de cultivo presente nos tubos com água destilada estéril e, em seguida, foi inoculado em frascos erlenmeyer $(500 \mathrm{~mL})$ contendo o meio de cultura líquido $(120 \mathrm{~mL})$ composto de $(\mathrm{p} / \mathrm{v})$ glicose $1,0 \%$, peptona $2,0 \%$, extrato de levedura $0,5 \%$, óleo de oliva, $1,0 \%, \mathrm{NaNO}_{3} 0,1 \%$, $\mathrm{KH}_{2} \mathrm{PO}_{4} 0,1 \% \mathrm{MgSO}_{4} \cdot 7 \mathrm{H}_{2} \mathrm{O} 0,05 \%$, em pH inicial 6,5 (tampão fosfato $0,1 \mathrm{M}$ ). Os frascos foram incubados em agitador rotativo, tipo shaker (Tecnal TE-421) a $35^{\circ} \mathrm{C}$ por $72 \mathrm{~h}$, com $130 \mathrm{rpm}$. Após este período, o meio foi filtrado sobre gazes e o caldo obtido denominado extrato enzimático bruto. A biomassa (peso seco) residual foi determinada gravimetricamente, após lavagem com água destilada, acetona e secagem em estufa à vácuo até peso constante. Para o estudo de estabilidade das enzimas, assim como para as reações de esterificação, a enzima foi utilizada na forma liofilizada. O seguinte procedimento foi realizado: ao extrato enzimático bruto coletado sob resfriamento foi adicionado sulfato de amônio em quantidade suficiente para fornecer $80 \%$ de saturação e mantido sob repouso por $24 \mathrm{~h}$ em geladeira $\left(5^{\circ} \mathrm{C}\right)$ para precipitação da enzima. O precipitado foi coletado por centrifugação a $7.000 \mathrm{rpm}$ por 15 min e dialisado contra solução tampão fosfato $\mathrm{pH} 7,0 \mathrm{com}$ membrana de acetato de celulose por $48 \mathrm{~h} \mathrm{a} 4{ }^{\circ} \mathrm{C}$. O dialisado foi liofilizado e o pó obtido denominado de lipase liofilizada bruta.

\section{Efeito da temperatura e do $\mathrm{pH}$ na estabilidade das enzimas}

Para verificar o efeito da temperatura, a lipase liofilizada bruta (0,2 g) adicionada a 3,0 $\mathrm{mL}$ de tampão fosfato de sódio $(0,2 \mathrm{M})$ com $\mathrm{pH}$ de 6,5 ( $\mathrm{pH}$ ótimo das enzimas conforme determinado por Silva et $a l .{ }^{19}$ ) foi incubada as temperaturas que variaram de 35 a $70{ }^{\circ} \mathrm{C}$ por $1 \mathrm{~h}$ em agitador rotativo a $70 \mathrm{rpm}$. Após o tratamento, $1 \mathrm{~mL}$ deste extrato foi acrescentado ao sistema de reação contendo o substrato, para se medir a atividade residual de hidrólise.

Para verificar o efeito do $\mathrm{pH}$, a lipase liofilizada bruta $(0,2 \mathrm{~g})$ foi adicionada a 3,0 mL de tampão nos seguintes valores de $\mathrm{pH}$ : solução tampão acetato $(0,2 \mathrm{M}) \mathrm{com} \mathrm{pH}$ de 5,5 , tampão fosfato de sódio $(0,2 \mathrm{M})$ com pH de 6,$0 ; 6,5 ; 7,0 ; 7,5$ e 8,0, e tampão carbonato-bicarbonato de sódio $(0,2 \mathrm{M}) \mathrm{com} \mathrm{pH}$ de 9,0 e 10,0 e em seguida incubadas à temperatura de $40^{\circ} \mathrm{C}$ (temperatura ótima das enzimas conforme determinado por Silva et al. ${ }^{19}$ ) por $1 \mathrm{~h} \mathrm{em}$ agitador rotativo a $70 \mathrm{rpm}$. Após o tratamento, $1 \mathrm{~mL}$ deste extrato foi acrescentado ao sistema de reação contendo o substrato para se medir a atividade residual de hidrólise.

\section{Estudo da capacidade de esterificação enantiosseletiva das lipases}

Essa capacidade foi avaliada a partir de duas reações de esterificação, utilizando os seguintes sistemas: (a) esterificação do $(R, S)$ ibuprofeno com 1-propanol como aceptor acila em meio contendo isoctano $^{20,21}$. Esta reação contendo o sistema composto de $(R, S)$ ibuprofeno (66 mM), 1-propanol $(66 \mathrm{mM})$, isoctano $(10 \mathrm{~mL}), 1$ $\mathrm{mL}$ de solução tampão fosfato de sódio $\mathrm{pH}$ 6,0 e $2 \%$ de peneira 
molecular $4 \AA$ (m/m) foi iniciada pela adição de $0,1 \mathrm{~g}$ de lipase (linhagens nativas e comerciais) e conduzida à $40^{\circ} \mathrm{C}$ em agitador rotativo tipo "shaker" com $130 \mathrm{rpm}$. Em diferentes intervalos de tempo, foram retirados $100 \mu \mathrm{L}$ da solução e adicionados a $1,4 \mathrm{~mL}$ de isoctano para análises cromatográficas posteriores; (b) esterificação do $(R, S)$-2-octanol com o ácido decanóico em meio contendo hexano ${ }^{22}$. Esta reação contendo o sistema composto de $(R, S)$-2octanol $(40 \mathrm{mM})$, ácido decanóico $(100 \mathrm{mM})$, hexano $(10 \mathrm{~mL})$ e $0,1 \mathrm{~g}$ de lipase (linhagens nativas e comerciais) foi conduzida nas mesmas condições descritas acima. Em diferentes intervalos de tempo, foram retiradas alíquotas de $50 \mu \mathrm{L}$ da solução para análises cromatográficas posteriores. As reações de esterificação, nas mesmas condições, também foram realizadas com as enzimas comerciais de Candida rugosa e de Candida antarctica (Novozyme 435) para comparação dos resultados. Experimentos sem adição da enzima foram preparados para verificar a porcentagem de esterificação espontânea do sistema (controle).

\section{Métodos analíticos}

\section{Determinação da atividade de hidrólise}

A determinação da atividade de hidrólise por titulometria é baseada no método proposto por Thomson et al. ${ }^{23}$, que se baseia na titulação com $\mathrm{KOH}$ dos ácidos graxos liberados pela ação da enzima lipase sobre triacilgliceróis presentes no óleo de oliva. A atividade foi determinada utilizando-se uma curva padrão de ácido oléico puro. Uma unidade de atividade lipolítica é definida como a quantidade de enzima que libera um micromol de ácidos graxo por min, nas condições de ensaio descritas. Foi usado como branco a mistura de reação em tempo zero. As análises foram realizadas em triplicata e expressas como média das determinações.

\section{Determinação da atividade específica}

A quantificação de proteínas totais foi realizada segundo o método de Lowry et al. ${ }^{24}$, usando albumina de ovo como padrão e medindo-se a absorbância a $280 \mathrm{~nm}$.

\section{Determinação dos valores de conversão, excessos}

enantioméricos e da razão enantiomérica

A capacidade enantiosseletiva das lipases foi determinada considerando-se os valores de conversão (c), excesso enantiomérico do substrato (ee $)_{\mathrm{s}}$, excesso enantiomérico do produto ( $\mathrm{ee}_{\mathrm{p}}$ ) e a razão enantiomérica (E) segundo cálculos proposto por Faber ${ }^{9}$. Para os cálculos foi utilizado o programa disponível na internet em http://www-org.tu-graz.ac.at ${ }^{25}$.

\section{Análises cromatográficas}

A quantidade de ibuprofeno que não reagiu e do $(R, S)$-éster propílico formado durante as reações foram quantificados por cromatografia a gás convencional. Foi utilizado um cromatógrafo gasoso da Chrompack (modelo CP 9001) equipado com detector de ionização de chama (FID) e coluna capilar de sílica fundida com fase estacionária de dimetilpolisiloxano CP-Sil 5 CB (10 m x $0,25 \mathrm{~mm} \times 0,12 \mu \mathrm{m})$. A temperatura do injetor foi $300{ }^{\circ} \mathrm{C}$, a do detector foi $350{ }^{\circ} \mathrm{C}$ e a da coluna, mantida a $150{ }^{\circ} \mathrm{C}$. O gás carreador foi hidrogênio com fluxo de $1,0 \mathrm{~mL} / \mathrm{min}$. A área dos picos foi calculada por meio do integrador (Chromato-Integrator) e expressa em porcentagem relativa. O tempo total de corrida foi de $5 \mathrm{~min}$, sendo o tempo de retenção do $(R, S)$-ibuprofeno de $1,122 \mathrm{~min}$ e do $(R, S)$-éster propílico do ibuprofeno de 1,314 min.

As formas enantioméricas do álcool foram quantificadas no mesmo equipamento utilizando uma coluna capilar quiral Beta Dex $^{\text {TM }} 120$ (Supelco Inc). A temperatura inicial da coluna foi de
$100{ }^{\circ} \mathrm{C}$ por $30 \mathrm{~min}$, aumentando gradativamente $5^{\circ} \mathrm{C}$ por min até $220^{\circ} \mathrm{C}$ permanecendo por $30 \mathrm{~min}$. A temperatura do detector foi de $250{ }^{\circ} \mathrm{C}$ e do injetor de $220^{\circ} \mathrm{C}$ empregando como gás de arraste o hidrogênio com fluxo de $1,0 \mathrm{~mL} / \mathrm{min}$. O tempo de retenção do $(R)$ 2-octanol foi de 31,243 min e do (S)-2-octanol foi de 32,893 min. A identificação dos picos foi realizada por comparação do tempo de retenção dos componentes da amostra com os de padrões autênticos injetados nas mesmas condições e a quantidade de cada enantiômero foi calculada a partir das áreas dos picos obtidos.

As formas enantioméricas, $(R)$-ibuprofeno e $(S)$-ibuprofeno, foram identificadas e quantificadas utilizando um sistema (CLAE) modelo LC-10 AD Shimadzu com detector de UV-VIS modelo SPD$10 v p$ e auto injetor modelo SIL-10AD $v p$, Shimadzu. A coluna usada foi de fase estacionária quiral tris-(3,5 dimetilfenil carbamato) de celulose Chiralcel OD (Daicel Chemical Industries, LTD). A fase móvel usada foi hexano/isopropanol/ácido trifluoracético na proporção de 100/1/0,1 v/v com fluxo de 1,0 mL/min em condição isocrática, o comprimento de onda monitorado foi de $254 \mathrm{~nm}$. O tempo total de corrida para cada amostra foi de $15 \mathrm{~min}$, sendo o tempo de retenção do $(R)$-ibuprofeno de 7,061 min e do $(S)$ ibuprofeno de 7,835 $\mathrm{min}$.

\section{RESULTADOS E DISCUSSÃO}

\section{Produção das enzimas e atividades enzimáticas}

Em trabalhos anteriores foi relatado o isolamento de 425 amostras de microrganismos ${ }^{2}$, a seleção e a caracterização cinética parcial de 3 fungos filamentosos produtores de lípase ${ }^{19,26}$, identificados como Aspergillus niger, Geotrichum candidum e Penicillium solitum. Em continuidade, a produção de lipases por estas cepas foi novamente realizada, e os dados referentes à biomassa obtida após fermentação em meio de cultivo líquido, assim como os valores referentes às unidades de atividade enzimática e atividades específicas estão apresentados na Tabela 1 .

Os valores de biomassa e, em especial, de atividade da enzima na hidrólise do óleo de oliva tem sido amplamente utilizados para efeito de comparação e seleção de cepas produtoras de lipase. Estes valores podem variar significativamente dependendo do tipo de fermentação, da composição do meio de cultivo e também de outras variáveis do processo fermentativo, tais como $\mathrm{pH}$, temperatura de incubação e presença de indutores da síntese de lipase como os óleos vegetais ${ }^{27}$.

Os maiores valores de biomassa (962 mg/100 mL de meio) e de atividade de enzima $(18,2 \mathrm{U} / \mathrm{mL})$ foram obtidos com a cepa de Aspergillus niger, seguida pelas cepas de Geotrichum candidum e Penicillium solitum. Em relação à produção de lipase por cepas de Aspergillus, os dados de crescimento e de atividade de hidrólise da lipase de Aspergillus niger estudada neste trabalho foram similares aos relatados recentemente por Mahadik et al. ${ }^{28}$ para a mesma espécie $(1.060 \mathrm{mg} / 100 \mathrm{~mL}$ de meio e $18,0 \mathrm{U} / \mathrm{mL}$, respectivamente), após $72 \mathrm{~h}$ de fermentação a $30{ }^{\circ} \mathrm{C}$ em meio de cultivo composto $(\mathrm{p} / \mathrm{v})$ de extrato de levedura $0,1 \%$, bactopeptona $0,5 \%$ adicionado de $1,0 \%$ de glicose, $1,0 \%$ de óleo de oliva, $0,5 \%$ de Triton $\mathrm{X}$ 100 e alguns sais minerias. O processo fermentativo descrito é semelhante ao usado neste trabalho, mas pode-se verificar que na composição do meio foram adicionadas quantidades menores de fontes de nitrogênio (extrato de levedura e peptona) e também a presença do emulsificante Triton. Os mesmos autores relataram que a atividade da enzima foi praticamente nula $(0,02 \mathrm{U} / \mathrm{mL})$ quando a fermentação foi realizada sem a adição do óleo de oliva ${ }^{28}$. Entretanto, valores inferiores de atividade de hidrólise foram relatados para as lipases produzidas pelos fungos Aspergillus niger $(7,6 \mathrm{U} / \mathrm{mL})$ e 
Tabela 1. Atividade de hidrólise das lipases obtidas de cepas fúngicas após $72 \mathrm{~h}$ de fermentação em meio de cultivo líquido a

\begin{tabular}{lcccc}
\hline Microrganismos & $\begin{array}{c}\text { Biomassa } \\
(\mathrm{mg})\end{array}$ & $\begin{array}{c}\text { Atividade da enzima }^{\mathrm{c}} \\
(\mathrm{U} / \mathrm{mL})\end{array}$ & $\begin{array}{c}\text { Proteínas totais }^{\mathrm{d}} \\
(\mathrm{mg} / \mathrm{mL})\end{array}$ & $\begin{array}{c}\text { Atividade específica }^{\mathrm{e}} \\
(\mathrm{U} / \mathrm{mg})\end{array}$ \\
\hline Aspergillus niger van Tieghem & $962 \pm 40$ & 18,2 & 32,6 & 0,56 \\
Geotrichum candidum Link ex Leman & $723 \pm 36$ & 12,8 & 30,4 & 0,42 \\
Penicillium solitum Westling & $656 \pm 38$ & 10,5 & 31,8 & 0,33 \\
\hline
\end{tabular}

${ }^{a}$ composição do meio (p/v) : glicose $1,0 \%$, peptona $2,0 \%$, extrato de levedura $0,5 \%$, óleo de oliva $1,0 \%, \mathrm{NaNO}_{3} 0,1 \%, \mathrm{KH}_{2} \mathrm{PO}_{4} 0,1 \%$ $\mathrm{MgSO}_{4} \cdot 7 \mathrm{H}_{2} \mathrm{O} 0,05 \%$; ${ }^{\text {b }}$ biomassa expressa em mg obtida de $100 \mathrm{~mL}$ de meio de cultivo; ${ }^{\mathrm{c}}$ atividade expressa em U/mL do extrato enzimático bruto; ${ }^{d}$ poteínas totais expressa em $\mathrm{mg} / \mathrm{mL}$ do extrato enzimático bruto e ${ }^{\mathrm{e}}$ atividade específica expressa em U/mg de proteínas totais

Aspergillus oryzae $(9,5 \mathrm{U} / \mathrm{mL})$ quando cultivados em meio de composição mais rica em fonte de carbono $(2,0 \% \mathrm{p} / \mathrm{v}$ de glicose $) \mathrm{e}$ fonte de nitrogênio (extrato de levedura, $1,0 \% \mathrm{p} / \mathrm{v}$ e peptona $2,0 \%$ $\mathrm{p} / \mathrm{v})$, adicionado de óleo de oliva (2,0\% p/v) após $48 \mathrm{~h}$ de incubação a $30^{\circ} \mathrm{C}^{29}$

A produção de lipase por Geotrichum candidum tem sido amplamente relatada na literatura, dada sua especificidade de hidrólise de acilgliceróis contendo ácidos graxos de cadeia longa com dupla ligação na posição $9^{30-32}$. Os valores de atividade do extrato enzimático bruto obtidos desta cepa $(12,8 \mathrm{U} / \mathrm{mL})$, assim como sua atividade específica $(0,42 \mathrm{U} / \mathrm{mg})$, foram praticamente o dobro dos valores relatados para o extrato bruto de uma cepa de Geotrichum sp (6,22 U/mL e 0,23 U/mg, respectivamente), após fermentação em meio líquido composto de farinha de soja e trigo em pó como fontes de carbono e extrato de levedura e $\mathrm{NH}_{4} \mathrm{NO}_{3}$ como fontes de nitrogênio ${ }^{33}$. Em contrapartida, a lipase de Geotrichum candidum comercializada pela Amano Pharmaceutical Co (GC-4), Japão, apresenta atividade específica de 80 e de $1.054 \mathrm{U} / \mathrm{mg}$ quando bruta e após purificada em fenil-sepharose (CL-4B), respectivamente ${ }^{34}$.

Rivera-Muños et al. ${ }^{35}$ testaram meio de cultivo sólido composto por farinha de trigo umidificada com solução contendo sais, como sulfato de magnésio e fosfato de potássio, e obtiveram baixos valores de atividade para as lipases de Aspergillus niger $(2,9 \mathrm{U} / \mathrm{mL})$ e Geotrichum candidum $(1,4 \mathrm{U} / \mathrm{mL})$. Para algumas espécies de Penicillium, como por ex. P. camembertii e P. candidum, os autores relataram a produção de lipases com atividade de cerca de $25 \mathrm{U} / \mathrm{mL}$.

Em relação as cepas de Penicillium, vários trabalhos foram encontrados envolvendo produção, caracterização e purificação de lipases de diferentes espécies, como P. citrinum $^{36}, P$. cyclopium $^{37}$,

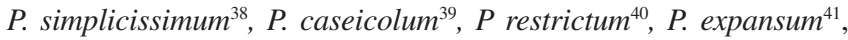
P. chrysogenum $^{42}$, P. roquefort ${ }^{43}$, P. camemberti $^{44}$, P. abeanum ${ }^{45}$, entre outras espécies ${ }^{46}$. Entretanto, parece que este é o primeiro relato sobre a produção de lipase pelo fungo Penicillium solitum. Comparados aos dados de crescimento e de atividade da lipase relatados para uma cepa brasileira de Penicillium restrictum (14,2 $\mathrm{mg}$ de biomassa/mL de meio e 13,0 U/mL, respectivamente) após fermentação em meio líquido composto de (p/v) óleo de oliva $1,0 \%$, peptona de carne $2,0 \%$, extrato de levedura $0,1 \%$ e $\mathrm{NaCl} 0,5 \%$, pode-se verificar que Penicillium solitum mesmo apresentando um crescimento menor $(656 \mathrm{mg}$ de biomassa/100mL de meio de cultivo), a atividade de hidrólise da lipase produzida é próxima $(10,5 \mathrm{U} / \mathrm{mL})$ à relatada para a lipase de Penicillium restrictum ${ }^{47}$. Considerando o coeficiente de produção de enzima (unidade de lipase produzida por $\mathrm{mg}$ de biomassa), esta cepa resultaria num coeficiente bem superior aos dados relatados pelos autores $\mathrm{s}^{40,47}$

O mesmo valor de atividade foi constatado para a lipase de $P$. aurantiogriseum $(13,0 \mathrm{U} / \mathrm{mL})$ após $72 \mathrm{~h}$ de fermentação em meio contendo (p/v) extrato de levedura $0,5 \%$, óleo de oliva $1,0 \%$, sais minerais e suplementação com solução $1,0 \%$ de sulfato de amônio ${ }^{48}$. Após otimização das condições de fermentação, os autores relata- ram o valor máximo de atividade de $25 \mathrm{U} / \mathrm{mL}$ para lipase de $P$. aurantiogriseum. No caso da lipase produzida por $P$. expansum, a atividade de hidrólise relatada pelos autores foi de apenas 6,1 U/ $\mathrm{mL}^{41}$. Portanto, comparados aos dados da literatura relacionados ao crescimento e à atividade de hidrólise, as três cepas fúngicas podem ser consideradas boas produtoras de lipase.

\section{Termoestabilidade das enzimas e estabilidade frente a diferentes valores de $\mathbf{p H}$}

A estabilidade frente a diferentes valores de temperatura e de pH são importantes parâmetros para uso destas enzimas em biocatálise orgânica. Existe um interesse especial em microrganismos capazes de produzir lipases alcalinas e termoestáveis ${ }^{49,50}$.

A curva de estabilidade das lipases incubadas por $1 \mathrm{~h}$ em temperaturas entre 35 e $70^{\circ} \mathrm{C}$ mantendo o $\mathrm{pH}$ constante de 6,5 (tampão fosfato de sódio 0,2 M), está ilustrada na Figura 1.

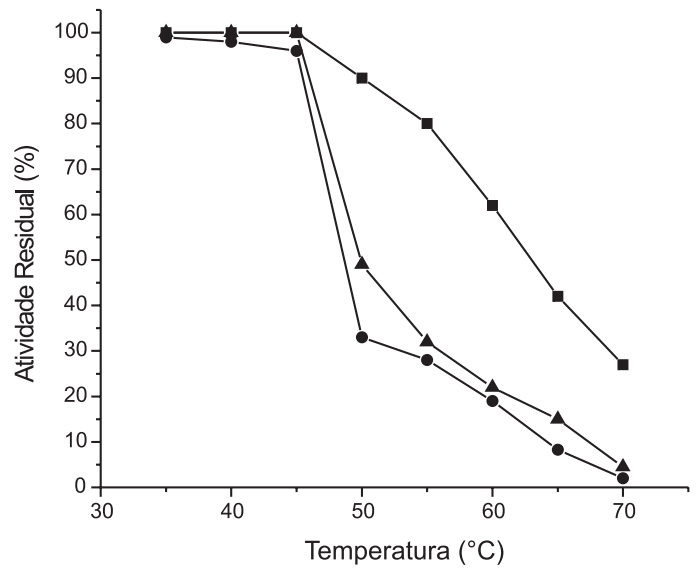

Figura 1. Estabilidade das lipases nativas após incubação em diferentes temperaturas. Lipases de (ם) Aspergillus niger, (-) Geotrichum candidum e (A) Penicillium solitum

Pode-se observar que estas enzimas são estáveis (mantêm 100\% da atividade) na faixa de temperatura de 35 a $45^{\circ} \mathrm{C}$. Uma diminuição considerável na atividade de hidrólise das lipases obtidas das cepas Geotrichum candidum e Penicillium solitum foi observada na temperatura de $50{ }^{\circ} \mathrm{C}$ (mantém aproximandamente 30 e $50 \%$ da atividade, respectivamente), sendo praticamente inativada a $70{ }^{\circ} \mathrm{C}$. Por outro lado, a lipase produzida pela cepa de Aspergillus niger merece destaque pelo seu comportamento termoestável comparado as outras testadas, mantendo 90 e $60 \%$ de sua atividade após incubação nas temperaturas de 50 e $60{ }^{\circ} \mathrm{C}$, respectivamente. Esta enzima é capaz de manter cerca de $30 \%$ de sua atividade quando tratada por $1 \mathrm{~h}$ a temperatura de $70{ }^{\circ} \mathrm{C}$.

A curva de estabilidade das lipases incubadas por $1 \mathrm{~h}$ em dife- 
rentes valores de $\mathrm{pH}$, mantendo-se a temperatura constante em $40{ }^{\circ} \mathrm{C}$, é apresentada na Figura 2.

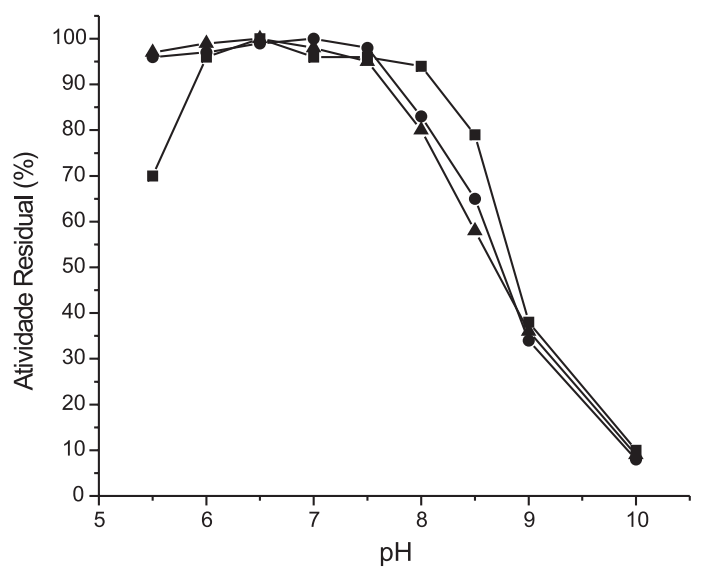

Figura 2. Estabilidade das lipases nativas após incubação em diferentes valores de pH. Lipases de (ロ) Aspergillus niger, (•) Geotrichum candidum $e(\mathbf{\Delta})$ Penicillium solitum

De acordo com a faixa de estabilidade, pode-se dividí-las em dois grupos: lipases de Geotrichum candidum e Penicillium solitum que são estáveis em valores de $\mathrm{pH}$ de 5,5 - 7,5 e lipase de Aspergillus niger que mantém sua atividade em valores de $\mathrm{pH}$ de 6,0-8,0. No valor de $\mathrm{pH}$ de 8,5 as lipases de Aspergillus niger, Penicillium solitum e Geotrichum candidum mantém 80, 65 e 58\% de suas atividades, respectivamente. Em valores superiores, $\mathrm{pH} 9$ e 10, todas as lipases apresentaram comportamento similar, sendo capazes de manter cerca de 35 e $10 \%$ de sua atividade, respectivamente.

É conhecido que as propriedades cinéticas e de estabilidade das enzimas podem variar significativamente, em função da origem ou mesmo entre isoformas produzidas por um mesmo microrganismo $^{51}$. Estas variações também dependem das condições do ensaio, como tempo de incubação, $\mathrm{pH}$ e temperatura, do método e do substrato utilizados, tornando, muitas vezes, a comparação difícil. Por ex., uma cepa de Aspergillus niger quando cultivada em meio contendo torta de gergelim (meio sólido) mostrou maior estabilidade térmica a $60^{\circ} \mathrm{C}$ (mantém $69 \%$ de sua atividade) que quando foi utilizado um meio de cultivo líquido a mesma temperatura (mantém $57 \%)^{52}$.

Dentre as variáveis do processo fermentativo, o binômio temperatura e $\mathrm{pH}$ tem sido amplamente estudado e considerado um fator de grande influência na atividade destas enzimas. As lipases produzidas por Aspergillus niger têm mostrado propriedades cinéticas e de estabilidade bastante diversificadas. Estas cepas são capazes de produzir lipases em valores de $\mathrm{pH}$ extremos, como $\mathrm{pH}$ de $1,5^{28}$ ou $\mathrm{pH}$ de 7,5 a $8,5^{29}$. Recentemente foi relatada uma lipase produzida por Aspergillus niger de alta estabilidade, que manteve $63 \%$ de sua atividade após $5 \mathrm{~h}$ de incubação a $70{ }^{\circ} \mathrm{C}$ em pH de 5,5, e que também se manteve estável em pH de 2,5 (70\% de atividade residual) até o valor de $\mathrm{pH}$ 9,0 (50\% de atividade residual) após 24 h de incubação a $30{ }^{\circ} \mathrm{C}^{28}$.

A estabilidade da lipase de Aspergillus niger estudada neste trabalho apresentou comportamento semelhante ao da descrita por Namboodiri e Chattopadhvaya ${ }^{53}$, a qual manteve $100 \%$ de sua atividade em $\mathrm{pH}$ de 5,0 a 7,5 e na faixa de temperatura de $35-55^{\circ} \mathrm{C}$ por $1 \mathrm{~h}$. Na temperatura de $60^{\circ} \mathrm{C}$ a enzima descrita pelos autores manteve $50 \%$ de sua atividade, enquanto a isolada no nosso laboratório, nas mesmas condições manteve $62 \%$ de sua atividade hidrolítica.
A estabilidade da lipase produzida pela cepa de $P$. solitum é concordante com os dados da literatura, que tem mostrado que a maioria das lipases obtidas de Penicillium não suportam $\mathrm{pH}$ acima de 7,540,50 e temperaturas acima de $45^{\circ} \mathrm{C}^{40,42}$, conforme observado. Os dados reportados para a cepa de Penicillium cyclopium mostram que a lipase é estável na faixa de $\mathrm{pH}$ entre 4,5 e 7,0, termoestável na faixa de temperatura de 25 a $40{ }^{\circ} \mathrm{C}$ em pH de 7,0 e inativada rapidamente acima de $40{ }^{\circ} \mathrm{C}^{54}$. Dados semelhantes foram encontrados para as lipases produzidas por Penicillium restrictum ${ }^{40}$ e Penicillium citrinum $^{36}$, as quais se mantiveram estáveis na faixa de $\mathrm{pH}$ de 7,0 a 8,0 a $30{ }^{\circ} \mathrm{C}$.

Um dos primeiros relatos das propriedades cinéticas da lipase de Geotrichum candidum mostraram que a enzima era estável na faixa de $\mathrm{pH}$ de 4,6 a 9,8 após tratamento por $24 \mathrm{~h}$ a $30{ }^{\circ} \mathrm{C}^{55}$. Outros relatos têm confirmado que esta enzima bruta apresenta estabilidade em valores de $\mathrm{pH}$ de 5,0 a 7,0 e retém $40 \%$ da atividade quando tratada a $50{ }^{\circ} \mathrm{C}^{33}$.

\section{Capacidade de esterificação enantiosseletiva das enzimas: conversão, excesso enantiomérico e razão enantiomérica}

A capacidade enantiosseletiva das lipases foi primeiramente avaliada através da reação de esterificação do ibuprofeno racêmico com o 1-propanol, na presença de isoctano. A taxa de esterificação (\% de conversão) em função do tempo de reação catalisada por estas enzimas é apresentada na Figura 3.

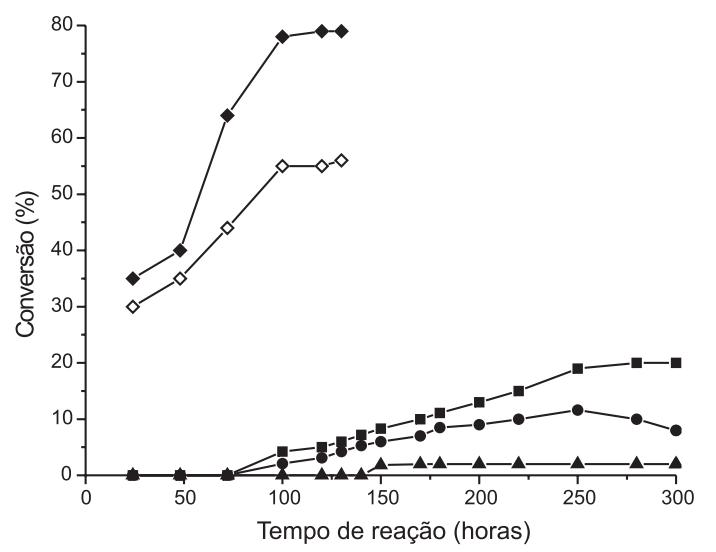

Figura 3. Reação de esterificação do ibuprofeno racêmico com 1-propanol catalisada pelas lipases selecionadas. Sistema reacional: (R,S)-ibuprofeno (66 mM), 1-propanol (66 mM), isoctano $(10 \mathrm{~mL}), 1 \mathrm{~mL}$ de tampão fosfato de sódio $\mathrm{pH}$ de 6,0 e 0,1 g de lipase, incubadas à $40{ }^{\circ} \mathrm{C}$. A conversão é dada como a porcentagem do ibuprofeno racêmico esterificado a cada tempo de

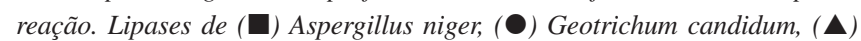
Penicillium solitum, $(\diamond)$ Candida rugosa $e(\diamond)$ Candida antarctica

Nas alíquotas recolhidas nos tempos de 24, 48 e 72 h não foi possível detectar a formação de $(R, S)$-éster propílico do ibuprofeno nas reações catalisadas pelas lipases nativas. Pode-se considerar que a esterificação se inicia após $100 \mathrm{~h}$ de reação com a lipase de Aspergillus niger (4,2\% de éster formado) e de Geotrichum candidum (2,1\% de éster formado) e após 140 h de reação com a lipase de Penicillium solitum (1,8\% de éster formado). A esterificação aumenta vagarosamente até a formação de 20 e $12 \%$ de $(R, S)$-éster propílico do ibuprofeno após $250 \mathrm{~h}$ de reação catalisada pelas lipases de Aspergillus niger e Geotrichum candidum, respectivamente. Após este período, a taxa de esterificação se mantém praticamente constante ou ocorre uma redução da quantidade de éster formado, provavelmente devido à reação 
reversa (hidrólise) em decorrência do aumento do conteúdo de água no sistema, como observado para a reação catalisada pela lipase de Geotrichum candidum. Em contrapartida, a lipase de Penicillium solitum não foi capaz de esterificar o ibuprofeno, mantendo praticamente $100 \%$ de ácido após 300 h de reação.

Nas reações controles, realizadas a fim de verificar a esterificação espontânea do sistema, observou-se que a porcentagem de esterificação foi praticamente nula (menos que $0,01 \%$ de éster formado) nas condições testadas.

Para efeito de comparação, as mesmas condições de reação foram realizadas para as lipases comerciais. Como era de se esperar, em concordância com vários relatos da literatura, as lipases de Candida têm mostrado alta capacidade na resolução de compostos da classe dos ácidos aril propiônicos ${ }^{16,56-59}$. Estas enzimas mostraram um alto rendimento de éster durante as primeiras $100 \mathrm{~h}$ de reação, resultando em aproximadamente 80 e $55 \%$ do $(R, S)$-éster do ibuprofeno com as lipases de Candida antarctica e C. rugosa, respectivamente. Estes valores são similares aos dados relatados por Arroyo et al. ${ }^{60}$ na esterificação do ibuprofeno racêmico com 1propanol em isoctano catalisada pela lipase bruta de Candida antarctica após 50 h de reação (80\% de conversão) e com os dados de Sánchez et al.$^{61}$ na esterificação do ibuprofeno racêmico com 1butanol em isoctano após $96 \mathrm{~h}$ de reação catalisada pela lipase bruta de Candida rugosa ( $54 \%$ de conversão).

Poucos trabalhos referentes à esterificação do ibuprofeno utilizando lipases provindas de outras fontes, como de Geotrichum candidum, Rhizopus arrhizus, Rhizomucor miehie, Aspergillus niger, Pseudomonas fluorences e algumas espécies de Penicillium foram encontrados ${ }^{5,62,63}$. Experimentos conduzidos por Mustranta ${ }^{56}$ mostraram que as lipases de Aspergillus niger e Geotrichum candidum não foram capazes de esterificar o ibuprofeno. Somente as de Candida cylindracea (rugosa) e, em especial, as fornecidas pela Biocatalysts e Meito-Sangyo foram eficientes na esterificação (42\% de conversão após $24 \mathrm{~h}$ de reação em sistema de reação isento de água) deste fármaco. A baixa capacidade de esterificação da lipase de Aspergillus niger também foi relatada para outros fármacos racêmicos pertencentes à mesma classe, como cetoprofeno ${ }^{57} \mathrm{e}$ naproxeno ${ }^{58,64}$.

Na Tabela 2 estão apresentados os parâmetros de conversão (c), de excesso enantiomérico do substrato $\left(\mathrm{ee}_{\mathrm{s}}\right)$, de excesso enantiomérico do produto ( $e_{\mathrm{p}}$ ) e a razão enantiomérica (E) resultante da reação de esterificação do $(R, S)$-ibuprofeno com 1-propanol. Para efeito de comparação, estes mesmos valores também estão sendo apresentados na Tabela 3 utilizando o sistema de reação composto de $(R, S)$-octanol e ácido decanóico após catálise com as lipases nativas e comerciais.
As lipases apresentaram diferenças significativas nos valores de c, ees, eep, E e na enantiopreferência em relação aos substratos racêmicos testados. As lipases que apresentam enantiopreferência ou enantiosseletividade são capazes de atuar preferencialmente em um dos enantiômeros da mistura racêmica o qual será convertido em seu correspondente éster. Em contrapartida, a reação com o enantiômero "discriminado" ocorre lentamente ou pode vir a não ocorrer. Este efeito é dependente em grande parte da procedência da enzima, ou seja, do tipo de microrganismo produtor, e está essencialmente relacionado ao arranjo estrutural do sítio ativo, de forma que este reconheça preferencialmente um dos enantiômeros ${ }^{65}$.

Conforme demonstrado na Tabela 2, a lipase de Aspergillus niger, que mostrou esterificar preferencialmente o $(R)$-ibuprofeno resultou em $6,1 \%$ de ee do $(S)$-ibuprofeno, a forma ativa do fármaco, com o valor de E de 1,8 após 250 h de reação com $20 \%$ de conversão do éster. A lipase de Geotrichum candidum embora tenha se mostrado capaz de esterificar o ibuprofeno (12,1\% de conversão), a reação ocorreu indiscriminadamente, ou seja, ocorre a formação de $(R)$-éster e de $(S)$-éster, levando consequentemente a baixo valor de excesso enantiomérico do ácido $(1,9 \%)$ e de E $(1,3)$. Em contrapartida, a lipase de Penicillium solitum foi incapaz de esterificar este fármaco nas condições testadas.

Trabalhos anteriores já haviam relatado a baixa capacidade destas enzimas na esterificação dos fármacos da classe dos ácidos aril-propiônicos. Valores inferiores de ee do $(S)$-ibuprofeno $(2,3 \%)$ e de conversão $(1,9 \%)$ foram relatados com a utilização da lipase de Aspergillus niger (Fluka) na esterificação do naproxeno racêmico com butanol em isoctano ${ }^{64}$. Taxa de conversão praticamente nula foi relatada com as lipases de Aspergillus niger (Amano) e Geotrichum candidum (Biocatalyst) na esterificação do ibuprofeno racêmico com álcool amílico em isoctano ${ }^{56}$. A utilização de uma cepa de Penicillium chrysogenum relatada por Cardenas et al. ${ }^{63}$ resultou em baixos níveis de conversão (3,7\% de éster após 336 h de reação) e de ee do ácido (ee (S)-ácido de 0,2\%). Em contrapartida, os autores relataram a obtenção de 49,5\% de éster após 144 h de reação com $62 \%$ de ee do $(R)$-ácido na reação catalisada pela lipase de Candida rugosa.

É importante lembrar que, a condição ideal para uma resolução enantiosseletiva é que somente um dos enantiômeros seja esterificado com o término da reação correspondendo a $50 \%$ de conversão. Com o uso da lipase de Candida rugosa, foi possível obter $50 \%$ de $(R, S)$-éster propílico após $60 \mathrm{~h}$ de reação, sendo que o $(S)$-ibuprofeno é em grande parte convertida para éster, mantendo $64,1 \%$ de $(R)$-Ibuprofeno sem reagir. Quando a reação se processa em tempos mais longos (100 h) o valor de E da enzima se mantém praticamente constante. Com o uso da lipase de Candida

Tabela 2. Conversão do éster (c), excesso enantiomérico do substrato (ee $)$, excesso enantiomérico do produto (ee ${ }_{\mathrm{p}}$ ) e razão enantiomérica (E) obtidos com as lipases nativas e comerciais na esterificação do $(R, S)$-ibuprofeno com 1-propanol na presença de isoctano

\begin{tabular}{|c|c|c|c|c|c|c|}
\hline Enzimas & $\begin{array}{c}\text { Tempo de reação } \\
\text { (h) }\end{array}$ & $\mathrm{c}(\%)^{\mathrm{a}}$ & $\mathrm{ee}_{\mathrm{s}}(\%)^{\mathrm{b}}$ & $\mathrm{ee}_{\mathrm{p}}(\%)^{\mathrm{c}}$ & $\mathrm{E}^{\mathrm{d}}$ & Enantiopreferência \\
\hline Aspergilus niger & 250 & 19,8 & 6,1 & 25,0 & 1,8 & $R$ \\
\hline Geotrichum candidum & 250 & 12,1 & 1,9 & 13,0 & 1,3 & $S$ \\
\hline Penicillium solitum & 250 & - & - & - & ND & - \\
\hline \multirow[t]{2}{*}{ Candida rugosa } & 60 & 49,7 & 62,1 & 62,0 & 7,9 & $S$ \\
\hline & 100 & 54,9 & 73,4 & 60,0 & 8,4 & \\
\hline Candida antarctica & 75 & 50,4 & 44,3 & 44,0 & 3,9 & $R$ \\
\hline (Novozymes 435) & 100 & 78,2 & 82,1 & 23,0 & 3,5 & \\
\hline
\end{tabular}

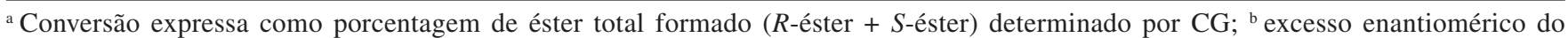
ibuprofeno (ee ${ }_{s}$ determinado por CLAE-quiral; ${ }^{c}$ excesso enantiomérico do éster de ibuprofeno (ee ${ }_{\mathrm{p}}$ ) calculado segundo ref. 25 ; ${ }^{\mathrm{d}}$ razão enantiomérica (E) calculado segundo ref. 25 e ND: valor não determinado 
Tabela 3. Conversão do éster (c), excesso enantiomérico do substrato $\left(e_{\mathrm{s}}\right.$ ), excesso enantiomérico do produto (ee ${ }_{\mathrm{p}}$ ) e razão enantiomérica (E) obtidos com as lipases nativas e comerciais na esterificação do $(R, S)$-2-octanol com o ácido decanóico na presença de hexano

\begin{tabular}{lcccccc}
\hline Enzimas & $\begin{array}{c}\text { Tempo de reação } \\
(\mathrm{h})\end{array}$ & $\mathrm{c}(\%)^{\mathrm{a}}$ & $\mathrm{ee}_{\mathrm{s}}(\%)^{\mathrm{b}}$ & $\mathrm{ee}_{\mathrm{p}}(\%)^{\mathrm{c}}$ & $\mathrm{E}^{\mathrm{d}}$ & Enantiopreferência $^{\mathrm{c}}$ \\
\hline Aspergilus niger & 100 & 41,8 & 56,1 & 77,0 & 13,2 & $R$ \\
Geotrichum candidum & 100 & 24,1 & 15,4 & 46,2 & 3,1 & $S$ \\
Penicillium solitum & 100 & 26,3 & 17,1 & 47,8 & 3,3 & $S$ \\
Candida rugosa & 100 & 45,6 & 44,2 & 52,0 & 4,8 & \\
Candida antarctica & 100 & 49,1 & 77,0 & 80,3 & 20 & $R$ \\
\hline
\end{tabular}

${ }^{\mathrm{a}}$ Conversão expressa como porcentagem de éster total formado ( $R$-éster $+S$-éster) determinado por CG; ${ }^{\mathrm{b}}$ excesso enantiomérico do álcool

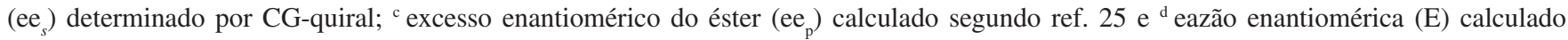
segundo ref. 25 .

antarctica, embora tenha sido obtido alto valor de ee do $(S)$ ibuprofeno $(82,1 \%)$, o valor de $\mathrm{E}(3,5)$ foi menor quando comparado ao da C. rugosa, devido a altas taxas de esterificação $(\sim 80 \%)$ após 100 h de reação. Mesmo com a obtenção de $50 \%$ de éster (após 75 h de reação), o ee obtido foi menor (44,3\% do $(S)$ ibuprofeno) e o valor de E também se manteve praticamente constante.

Em trabalho publicado recentemente de esterificação enantiosseletiva de um derivado do ácido fenoxipropiônico, usado como herbicida, utilizando as lipases comerciais de Candida rugosa (Sigma - TipoVII) e Candida antarctica (Novozyme 435 - Tipo B), as mesmas usadas neste trabalho, os autores relataram que a Novozyme 435 mostrou altíssima capacidade de esterificação (70\% após $1,5 \mathrm{~h}$ na presença da mistura de hexano $+\mathrm{CCl}_{4}$ ), com baixa enantiosseletividade (ee do $(S)$-ácido $=22$ ). Em contrapartida, a lipase de Candida rugosa foi capaz de esterificar $50 \%$ do substrato $((R)$ ácido) após 24 h de reação, resultando $100 \%$ de ee do $(S)$-ácido ${ }^{59}$.

Alguns trabalhos de resolução deste fármaco têm sido realizados utilizando a Candida antarctica como biocatalisador ${ }^{60,66}$, que apresenta a vantagem de resultar na forma ativa $(S)$-ibuprofeno. A enantiopreferência destas enzimas na esterificação do $(R)$-ibuprofeno é interessante, pois permite a obtenção da forma ativa $(S)$ ibuprofeno ativa sem necessidade de etapas químicas adicionais.

Conforme demonstrado na Tabela 3, a lipase de Aspergillus niger tem, claramente, preferência pelo $(R)$-enantiômero do álcool resultando em $56,1 \%$ de ee do (S)-2-octanol, com o valor de E de 13,2 após 100 h de reação. Alto valor de ee do (S)-2-octanol $(87,1 \%)$ também foi obtido com a lipase comercial de Candida antarctica com 52,1\% de conversão e E de 20 após o mesmo tempo de reação. Em contrapartida, as lipases de Geotrichum candidum, Penicillium solitum e Cândida rugosa (comercial) que apresentaram enantiopreferência pelo $(S)$-enantiômero do álcool resultaram em baixos valores de ee e de E.

Embora a eficiência na resolução de um racemato seja caracterizada pelo excesso enantiomérico, a razão enantiomérica (E) significa um parâmetro muito importante. Um valor elevado de E para um dado par (E-S) é essencial para o sucesso de uma resolução cinética, já que isto assegura não apenas um excesso enantiomérico elevado, mas também um rendimento proporcionalmente alto ${ }^{9}$. Para propósitos práticos, um valor de E abaixo de 10 para qualquer biotransformação torna-se inviável como um processo enantiosseletivo. Por outro lado, este pode ser considerado bom se estiver situado entre 10 e 30 e acima deste valor pode ser considerado excelente ${ }^{9,25}$.

A lipase de Candida antarctica (Novozymes 453) tem sido relatada pela alta eficiência na esterificação de diferentes álcoois secundários racêmicos e ácidos carboxílicos. O valor de E na esterificação do 2-octanol racêmico com o ácido decanóico foi de aproximadamente 40, conforme relatado por Wehtje et al. ${ }^{22}$ e variou de 8 a 760 na esterificação do 2-butanol e 3,3 dimetil-2-butanol, com o ácido octanóico, respectivamente, conforme relatado por Raza et al. ${ }^{67}$.Todas as reações citadas por estes autores utilizaram meio orgânico nas reações enantiosseletivas.

Tem-se observado que mesmo as enzimas que apresentam baixos valores de E têm sido utilizadas com sucesso nas resoluções de sustratos racêmicos, considerando-se que diferentes condições de reação, tais como tipo de solvente, atividade de água e temperatura de reação interferem significativamente nos valores de $\mathrm{E}^{56,65,66,68} \mathrm{e}$, portanto, estas condições podem ser otimizadas. Modificações químicas destas enzimas com inclusão de grupamentos hidrofóbicos ${ }^{69}$, a formação de complexos com ciclodextrinas ${ }^{70}$, com glicolipídeos ${ }^{71}$ ou com dextranas ${ }^{72}$ são capazes de aumentar significativamente os valores de E.

$\mathrm{O}$ uso em escala industrial de enzimas purificadas, em especial as obtidas de Candida rugosa e Candida antarctica, embora extensivamente relatadas na resolução de muitos racematos, não parece muito atrativo do ponto de vista econômico, dado o custo das técnicas de purificação e imobilização destas enzimas. Para utilização de enzimas em biocatálise, desde que as impurezas presentes no extrato enzimático não interfiram na reação catalisada e na utilização do produto final, processos parciais de purificação têm se mostrado suficientes. Altos valores de ee do ácido não esterificado foram relatados utilizando as espécies de Candida na forma bruta para catalisar as reações de esterificação do ibuprofeno ${ }^{59,73}$.

\section{CONCLUSÕES}

Das fontes microbianas produtoras de lipases relatadas até o presente, poucas tem sido utilizadas eficientemente na resolução de diferentes racematos, como por ex. na resolução dos fármacos racêmicos. Dos fungos testados no presente trabalho, a lipase produzida pela cepa de Aspergillus niger mostrou algumas propriedades desejadas para seu uso em biocatálise: alta atividade de hidrólise, comportamento termoestável e, aliada a estas vantagens, esta enzima apresentou boa capacidade de esterificação do ibuprofeno racêmico com enantiopreferência para esterificar a forma $(R)$-ibuprofeno aumentando, portanto, a quantidade da forma $(S)$-ácida ativa na mistura racêmica. A enantiopreferência desta enzima, confirmada através da reação de esterificação do $(R, S)$-octanol com o ácido decanóico, resultou em altos valores de ee do $(S)$-2-octanol e de E. Até o momento, obteve-se baixos valores de excesso enantiomérico do fármaco de interesse, $(S)$-ibuprofeno, nas condições utilizadas. Estudos envolvendo modificações das condições de reação, como atividade de água, temperatura da reação, tipos de solventes e diferentes concentrações da enzima, têm sido realizados na tentativa de superar os baixos valores de ee do composto desejado. 
Considerando ainda que são poucos os relatos de tentativa de utilização de outras fontes de lipase que não as espécies de Candida na resolução destes fármacos, o aumento da oferta de novas lipases pode contribuir para a resolução enantiomérica de racematos em que a propriedade farmacológica é atribuída a somente um dos enantiômeros.

\section{AGRADECIMENTOS}

Aos auxílios financeiros recebidos da FAPESP, CAPES e USFPROPEP. Agradecem de forma especial a cooperação da Dra. $\mathbf{M}^{\mathrm{a}}$. do C. Basílio (ITQB/UNL) e Dr. J. L. B. Ferreira, do Laboratório do Centro de Micologia da Universidade de Lisboa, em Portugal pela identificação dos microrganismos usados no trabalho.

\section{REFERÊNCIAS}

1. Demirjian, D. C.; Shah, P. C.; Moris-Vas, F.; Biocatalysis- From discovery To Application 1999, 200, 1.

2. Campos, P. R. B.; Oliveira, B. F.; Noffs, M. D. A.; Carvalho, P. O.; Lecta 2002, 20, 7 .

3. Carvalho, P.O.; Campos, P. R. B.; Noffs, M. D.; Oliveira, J. G.; Shimizu, M. T.; Silva, D. M.; Quim. Nova 2003, 26, 75

4. Carvalho, P. O.; Pastore, G. M.; Food Biotechnol. 1998, 12, 57.

5. Macedo, G. A.; Pastore, G. M.; Food Sci. Biotechnol. 2004, 13, 21.

6. Jaeger, K. E.; Ransak, S.; Koch, H. B.; Ferrato, F.; Dijkstra, B. W.; FEMS Microbiol. Rev. 1994, 15, 29.

7. Vulfson, E. N. Em Lipases: Their Structure, Biochemistry and Application; Wooley, P.; Petersen, S. B., eds.; Cambridge University Press: Great Britain, 1994.

8. IwaI, M.; Tsujisaka, Y. Em Fungal Lipase; Brockman, H. L., ed.; Elsevier: Amsterdam, 1984

9. Faber, K.; ed. Em Biotransformation in Organic Chemistry; $4^{\text {a }}$ ed.; Springer-Verlag: Berlin, 2000.

10. Maier, N. M.; Franco, P.; Lindner, W.; J. Chromatogr., A 2001, 906, 3.

11. Caldwell, J.; Hutt, A. J.; Gigleux-Fournel, S.; Biochem. Pharmacol. 1988, $37,105$.

12. Neupert, W.; Brugger, R.; Euchenhofer, C.; Brune, K.; Geisslinger, G. Br.; J. Pharmacol. 1997, 122, 487.

13. Valentine, R.; Tese de Doutorado, University of Pittsburgh, Alemanha, 2002.

14. Bonneau P. R.; Martin, R.; Lee T.; Sakowicz, R.; Martichonok, V.; Hogan J. K.; Gold, M.; Jones, J. B.; J. Braz. Chem. Soc. 1996, 7, 357.

15. Saxena, R. K.; Ghosh, P. K.; Gupta, R.; Davidson, W. S.; Curr. Sci. 1999. 77, 101.

16. Margolin, A. L.; Enzyme Microb. Technol. 1993, 15, 266.

17. Tsai, S.; Tsai, C.; Chang, C.; Appl. Biochem. Biotechnol. 1999, 80, 205.

18. Chamorro, S.; Alcántara, A. R.; de la Casa, R. M.; Sinisterra, J. V.; SanchézMontero, J. M.; J. Mol. Catal. B: Enzym. 2001, 11, 939.

19. Silva, D. M.; Dissertação de Mestrado, Universidade São Francisco, Bragança Paulista, Brasil, 2004.

20. Arroyo, M.; Moreno, J. M.; Sinisterra, J. V.; J. Mol. Catal. A: Chem. 1995, 97, 195.

21. Cardenas, F.; Castro-Alvarez, M. S.; Sanchez- Montero, J. M. S.; Sanchez, A.; Sinisterra, J. V.; Valmaseda, M.; Elson, S. W.; Alvarez, E.; Enzyme Microb. Technol. 2001, 28, 145 .

22. Wehtje, E.; Costes, D.; Adlercreutz, P.; J. Mol. Catal. B: Enzym. 1997, 3, 221.

23. Thomson, C. A.; Delaquis, P. J.; Mazza, G.; Crit. Rev. Food Sci. Nutr. 1999, $39,165$.

24. Lowry, O. H.; Rosenbrough, N. J.; Farr, A. L.; Randall, R. J.; J. Biol. Chem. 1951, 193, 265.

25. http:www-org.tu-graz.ac.at, acessada em Julho de 2004

26. Silva, D. M.; Carvalho, P. O.; Oliveira, J. G.; Resumos do $2^{\circ}$ Encontro de Pós-Graduação Stricto Sensu, Itatiba, Brasil, 2003.

27. Pokorny, D.; Frederich, J.; Cimerman, A.; Biotechnol. Lett. 1994, 16, 363.

28. Mahadik, N. D.; Puntambekar, U. S.; Bastawde, K. B.; Khire, J. M.; Gokhale, D. V.; Process Biochem. 2002, 38, 715.

29. Ionita, A.; Moscovici, M.; Popa, C.; Vamanu, A; Popa, O.; Dinu, 1. ; J. Mol. Catal. B: Enzym. 1997, 3, 147.
30. Jensen, R. G.; Lipids 1974, 9, 149.

31. Macrae, A. R.; Hammond R. C.; Biotechnol. Genetic Eng. Rev. 1985, 3, 193.

32. Sugihara, A.; Shimada, Y.; Nakamura, M.; Nagao, T.; Tominaga, Y.; Protein Eng. 1994, 7, 585

33. Macedo, G. A.; Park, Y. K.; Pastore, G. M.; Rev. Microbiol. 1997, $28,90$.

34. Hedrich, H. C.; Spener, F.; Menge, U.; Hecht, H-J.; Schmid, R. D.; Enzyme Microb. Technol. 1991, 13, 840.

35. Rivera-Muñoz, G.; Tinoco-Valencia, J. R.; Sánchez, S.; Farrés, A.; Biotechnol. Lett. 1991, 13, 277.

36. Maliszewska, I.; Mastalerz, P.; Enzyme Microb. Technol. 1992, 14, 190.

37. Ibrik, A.; Chahinian, H.; Rugani, N.; Sarda, L.; Comeau, L. G.; Lipids 1998, $33,377$.

38. Sztajer, H.; Lunsdorf, H.; Erdmann, H.; Menge, U.; Schmid, R.; Biochim. Biophys. Acta 1992, 1124, 253.

39. Alhir, S.; Markakis, P.; Chadan, R. C.; J. Agric. Food Chem. 1990, 38, 598.

40. Sant'anna, Jr. G. L.; Freire, D. M. G.; Gomes, P. M.; Bon, E. P. S.; Rev. Microbiol. 1997, 28, 6 .

41. Stöklein, W.; Sztajer, H.; Menge, U.; Schmid, R. D.; Biochim. Biophys. Acta 1993, 1168, 181.

42. Ferrer, M.; Plou, F. J.; Nuero, O. M.; Reyes, F.; Ballesteros, A.; J. Chem. Technol. Biotechnol. 2000, 75, 569.

43. Mase, T.; Matsumiya, Y.; Matsuura, A.; Biosci. Biotechnol. Biochem. 1995, $59,329$.

44. Isobe, K.; Nokihara, K.; Yamagushi, S.; Mase, T.; Schmid, R. D.; Eur. J. Biochem. 1992, 203, 233.

45. Sugihara, A.; Shimada, Y.; Takada, N.; Nagao, T.; Tominaga, T.; J. Ferment Bioeng. 1996, 82, 498.

46. Yadav, R. P.; Saxena, R. K.; Gupta, R.; Davidson, S.; Folia Microbiol. 1998, 43, 373.

47. Freire, D. M. G.; Teles, E. M. F.; Bon, E. P. S.; Sant'anna Jr., G. L.; Appl. Biochem. Biotechnol. 1997, 63, 409.

48. Lima, V. M. G.; Krieger, N.; Sarquis, M. I. M.; Mitchell, D. A.; Ramos, L. P.; Fontana J. D.; Food Technol. Biotechnol. 2003, 41, 105.

49. Ema, T.; Kageyama, M.; Korenaga, T.; Sakai, T.; Tetrahedron: Asymmetry 2003, 14, 3943.

50. Hou, C. T.; J. Ind. Microbiol. 1994, 13, 242.

51. Lopez, N.; Pernas, M. A.; Pastrana, L. M.; Sanchez, A.; Valero, F.; Rua, M. 1.; Biotechnol. Prog. 2004, 20, 65.

52. Kamini, N. R.; Maia, J. G. S.; Puvanakrishnan, R.; Process Biochem. 1998, 33,505 .

53. Namboodiri, V. M. H.; Chattopadhavaya, R.; Lipids 2000, 35, 495.

54. Chahinian, H.; Vanot, G.; Ibrik, A.; Rugani, N.; Sarda, I.; Comeau, 1. C.; Biosci. Biotechnol. Biochem. 2000, 64, 215.

55. Tsujisaka, Y.; Iwai, M.; Tominaga, Y.; Agr. Biol. Chem. 1973, 37, 1457.

56. Mustranta, A.; Appl. Microbiol. Biotechnol. 1992, 38, 61.

57. D’ Antona, N.; Lombardi, P.; Nicolosi, G.; Salvo, G.; Process Biochem. 2002, 38, 373 .

58. Shang, C-S.; Hsu, C-S.; Biotechnol. Lett. 2003, 25, 413.

59. Ujang, Z.; Husain, W. H.; Seng, M. C.; Rashid, A. H. A.; Process Biochem. $\mathbf{2 0 0 3}, 38,1483$.

60. Arroyo, M.; Montero, J. M. S.; Sinisterra, J. V.; Enzyme Microb. Technol. 1999, 24, 3 .

61. Sánchez, A.; Valero, F.; Lafuente, J.; Solà, C.; Biotechnol. Lett. 1998, 20, 1145.

62. Sánchez, A.; Valero, F.; Lafuente, J.; Solà, C.; Enzyme Microb. Technol. 2000, 27, 157.

63. Cardenas, F.; Alvarez, E.; Castro-Alvarez, M. S.; Sanchez- Montero, J. M. S.; Valmaseda, M.; Elson, S. W.; Sinisterra, J. V.; J. Mol. Catal. B: Enzym. 2001, 14, 111.

64. Tsai, S. W.; Wei, H. J.; Enzyme Microb. Technol. 1994, 16, 328.

65. Costa, V. E. U., de Amorim, H. L. N.; Quim. Nova 1999, 22, 863.

66. Pepin, P.; Lortie, R.; Biotechnol. Bioeng. 1999, 63, 504.

67. Raza, S.; Fransson, L.; Hult, K.; Protein Sci. 2001, 10, 329.

68. Ducret, A.; Traani, M.; Lortie, R.; Enzyme Microb. Technol. 1998, 22, 212.

69. Ueji, S. I.; Ueda, A.; Tanaka, H.; Watanabe, K.; Okamoto, T.; Ebara, Y.; Biotechnol. Lett. 2003, 25, 83 .

70. Ghanem, A.; Org. Biomol. Chem. 2003, 1, 1282.

71. Okahata Y.; Fujimoto, Y.; Ikiro, A.; J. Org. Chem. 1995, 60, 2244.

72. De La Casa, R. M.; Guisán, J. M.; Sánches-Montero, J. M.; Sinisterra, J. V.; Enzyme Microb. Technol. 2002, 30, 30.

73. Sánchez, A.; Ferrer, P.; Serrano, A.; Valero, F.; Solà, C.; Pernas, M.; Rúa, M. 1.; Fernandez-Lafuente, R.; GuIsán, J. M.; Casa, R. M.; Sinisterra, J.V.; Sánchez-Montero, J. M.; J. Biotechnol. 1999, 69, 169. 